\title{
Congenital tremor in piglets: Is bovine viral diarrhea virus an etiological cause?
}

\author{
Marina Lopes Mechler ${ }^{a}$, Felipe dos Santos Gomes ${ }^{a}$, Karla Alvarenga Nascimento ${ }^{a}$, \\ Andressa de Souza-Pollo ${ }^{\text {, }}$, Felipe Ferreira Barbosa Pires ${ }^{\text {a }}$, Samir Issa Samara ${ }^{a}$, \\ Edviges Maristela Pituco ${ }^{\mathrm{b}}$, Luís Guilherme de Oliveira ${ }^{\mathrm{a}, *}$ \\ a São Paulo State University (Unesp), School of Agricultural and Veterinarian Sciences (FCAV). Via de Acesso Prof. Paulo Donato Castellane s/n, Jaboticabal, SP 14884- \\ 900, Brazil \\ ${ }^{\mathrm{b}}$ Biological Institute of São Paulo, Av. Conselheiro Rodrigues Alves, 1252 - Vila Mariana, São Paulo, SP, 04014-002, Brazil
}

\section{A R T I C L E I N F O}

\section{Keywords:}

Cerebellar hypoplasia

Experimental infection

Intrauterine inoculation

Myoclonus

Piglets

\begin{abstract}
A B S T R A C T
Congenital tremor in pigs involves several etiologies, including pestivirus, which may cause neurological injuries in different animal species. To evaluate whether bovine viral diarrhea virus (BVDV), an important pestivirus, is one of the etiological agents of congenital tremor in swine, gilts and the fetuses were challenged at 45 days of gestation with BVDV-2. Four pregnant gilts were inoculated oronasally, four gilts underwent fetal intrauterine inoculation, and two gilts constituted the control group. Antibody titers were determined by virus neutralization (VN), and viral RNA was detected by RT-PCR. Blood samples were collected from all gilts and piglets born to obtain whole blood and serum for analysis. One third of the neonates were euthanized at three days old, and samples of the encephalon, brain stem and spinal cord were collected for anatomopathological evaluation and viral RNA detection. The piglets that remained alive were clinically evaluated every day, and blood sampling was performed regularly for 35 days. The piglets from gilts in both inoculation treatment groups showed no clinical neurological signs and were born with no viral RNA in their blood and organs. Piglets born from oronasally inoculated gilts did not present antibodies against BVDV-2 at birth, although they were acquired by passive maternal transfer. In contrast, intrauterine-inoculated piglets were born with high antibody titers (80 to 640) against the agent, which remained high until the end of the experimental period. Microscopically, no noticeable changes were observed. Macroscopically, 29.5\% of the total piglets euthanized, from both inoculation groups, were born with a low cerebellar:brain ratio. Nevertheless, some piglets had a high cerebellar:brain ratio, indicating the need for standardizing this value. Thus, it was concluded that BVDV is not an etiological agent for congenital swine tremor.
\end{abstract}

\section{Introduction}

The genus Pestivirus belongs to the Flaviviridae family, which consists of classical swine fever virus (CSFV), bovine viral diarrhea virus (BVDV) and border disease virus (BDV) (Hoehe and Brito, 2012; Ridpath et al., 2012). BDV and BVDV may occasionally infect different host species (buffalo, sheep, goats and pigs) under natural conditions (Ridpath et al., 2012). Cerebellar hypoplasia and hypomyelination are common findings caused by different pestiviruses. BVDV can be transmitted by direct or indirect contact between the animals. The virus can be shed through nasal, ocular, genital and oral secretions, milk, semen, urine and feces, and vertical transmission to embryos/fetuses is common in pregnant cows (Thurmond, 2005). In bovine herds infected by BVDV, the most frequently described fetal malformations are cerebellar hypoplasia, hydrocephalus, microcephaly, poor myelinization of the spinal cord, retinal atrophy or dysplasia, microphthalmia, cataracts, thymic hypoplasia, hypotrichosis, brachygnathia and arthrogryposis (Ridpath et al., 2012).

Diseases that affect myelin sheath formation or nerve synapses alter electrical impulses in neurons, leading to tremors (Scarratt, 2004). Congenital tremor (CT) is characterized by head and limb tremors in newborns (Edwards and Mulley, 1999). This pathology is associated with demyelination in the brain and spinal cord and is clinically observed as tremor outbreaks in neonatal piglets that last for a limited period of time but may persist until the age of slaughter (Blomström et al., 2014). In addition, it is known that clinical signs of congenital

\footnotetext{
* Corresponding author.

E-mail address: luis.guilherme@unesp.br (L.G.d. Oliveira).
} 
tremor are associated with varying degrees of hypomyelinogenesis in the spinal cord or brain (Schwarz et al., 2017). Recent studies have identified a new pestivirus, known as atypical porcine pestivirus (APPV), which causes congenital tremor in piglets. APPV is present worldwide in swine herds and leads to moderate hypomyelination of the white matter of the cerebellum and spinal cord. The virus has been determined to be widely distributed among herds, with great variability among the strains, and has been found in Spain, the United States, Germany, the Netherlands, Austria, China and, recently, in Brazil (Hause et al., 2015; Arruda et al., 2016; Schwarz et al., 2017; Gatto et al., 2017). In these studies, APPV was able to cause congenital tremors in pigs, leading to malnutrition and death of the affected piglets.

It is known that CSFV is capable of causing congenital tremors in piglets infected by the intrauterine route, and it can lead to the birth of weak offspring, congenital malformations, abortions and the birth of persistently infected animals (OIE, 2015b). As with CSFV, Tunca et al. (2006) reported that the most common malformations in bovine fetuses transplacentally infected with BVDV are cerebellar hypoplasia and hypomyelination. BVDV infections in young pigs usually do not show clinical signs; however, reproductive problems, the birth of weak piglets, abortions and fetal mummification have been reported in adult animals (Vannier and Albina, 1999). In a previous study, pregnant sows were inoculated experimentally with BVDV-1 on the 65th day of gestation (Walz et al., 2004), but no relevant findings were observed; thus, there is a need for a broader analysis of the application of several isolates at different times of gestation to clarify the consequences of BVDV infection in pigs.

Cerebellar hypoplasia, hypomyelination, vertical transmission and the various manifestations of BVDV infection have been reported in cattle, but studies of pigs are scarce. To the best of our knowledge, this study is the first to use intrauterine inoculation of BVDV in swine to determine if this virus is a possible etiological agent of congenital tremors and whether it has the capacity to cause lesions in the central nervous system (CNS) of swine neonates and cerebellar hypoplasia.

\section{Materials and methods}

\subsection{Selection of animals and experimental design}

Ten commercial primiparous pigs, aged 180 days, weighing between 90 and $100 \mathrm{~kg}$ and free of CSFV, were acquired from a company specializing in the breeding and production of pigs in a region also free of CSFV. The gilts were vaccinated against reproductive diseases (parvovirus, leptospirosis and erysipelas) and were submitted to a natural breeding procedure with the same boar. All gilts were serologically negative for BVDV-1 and BVDV-2. The study involved three experimental groups. In the first group, four gilts (1, 2, 3 and 4) were oronasally inoculated with BVDV-2 to simulate natural infection pathways, which allows the maternal immune system to interfere with the dynamics of infection. In the second group, four gilts (5, 6, 7 and 8) underwent fetal intrauterine inoculation to evaluate the direct effects of the virus on the fetus and excluding effects from the placental barrier and the maternal immune system. The third group constituted the control group and included two gilts (9 and 10). These experiments were conducted in gilts at 45 days of gestation. All animals were housed under the same conditions, but the control group was isolated from the others, and all were fed according to the gestational stage.

Oronasal inoculation was performed by administering the inoculum in $15 \mathrm{ml}$ of Eagles minimal essential medium (EMEM), $10 \mathrm{ml}$ of which was instilled by syringe into the nostrils, and $5 \mathrm{ml}$ was administered orally, according to Cabezón et al. (2010). All gilts underwent blood sampling at intervals of $72 \mathrm{~h}$ until two weeks before delivery to observe the occurrence of viremia and seroconversion. The blood samples were collected with sterile disposable syringes free of anticoagulants and were obtained from puncture of the jugular vein with $25 \mathrm{gax} 7 \mathrm{~mm}$ needles. Blood was deposited in sterile EDTA tubes to obtain whole blood and in anticoagulant-free tubes, followed by centrifugation at $1500 \mathrm{x} g$ for $10 \mathrm{~min}$, to obtain blood serum. The whole blood and serum samples were stored as duplicates in $2.0 \mathrm{ml}$ graduated microtubes and stored at $-80^{\circ} \mathrm{C}$ and $-20^{\circ} \mathrm{C}$, respectively, until analysis was performed.

For intrauterine inoculation, the pregnant sows underwent a laparotomy in which each fetus received the inoculum in their respective amniotic vesicles. Pre-anesthetic induction was performed with an intramuscular injection of a combination of ketamine and midazolam at doses of $3 \mathrm{mg} / \mathrm{kg}$ and $0.5 \mathrm{mg} / \mathrm{kg}$, respectively. After induction, venous access via the medial or lateral ear vein was prepared for anesthetic maintenance with a continuous infusion of propofol at $4 \mathrm{mg} / \mathrm{kg}$. Each gilt was placed in left lateral recumbency, and the right abdomen was prepared for aseptic laparotomy. Local nerve block was then performed with $2 \%$ lidocaine, not exceeding $7 \mathrm{mg} / \mathrm{kg}$, with $3 \mathrm{ml}$ of the same used for lateral thoracic nerve block. To access the body cavity, a paramedian incision of approximately $25 \mathrm{~cm}$ was made, preserving the mammary tissue. The uterus was externalized, and each fetus received $0.5 \mathrm{ml}$ of the same viral solution in its respective amniotic vesicle using a $29 \mathrm{G}$ needle. The abdominal wall was sutured in three layers using synthetic, absorbable sutures. Each procedure took approximately $1 \mathrm{~h}$.

The control gilts received $15 \mathrm{ml}$ of placebo, administered with syringes oronasally, with $10 \mathrm{ml}$ of only EMEM instilled into the nostrils and $5 \mathrm{ml}$ instilled orally. These gilts also went through blood sampling at intervals of $72 \mathrm{~h}$.

\subsection{Inoculum}

The inoculum was isolated from a field sample (BVDV SV 260, genotype 2 non-cytophatic) of a clinical case of bovine viral diarrhea (Vogel et al., 2001; Flores et al., 2005). A viral dose with a titration of $10^{5,5} \mathrm{TCID}_{50} / \mathrm{ml}$ of BVDV-2 cultured on Madin-Darby Bovine Kidney (MDBK) cells was administered. The inoculum was tested on a calf, confirming the capacity to cause viremia and lead to seroconversion.

\subsection{Physical examination and sampling}

Pregnancy was monitored for any changes, and deliveries were attended to ensure that the piglets born did not ingest colostrum prior to the first blood collection, and that they received neonatal care at birth. Of the live-born piglets, $1 / 3$ of each litter was randomly selected for euthanasia and necropsy on the third day after birth, such that clinical observations were possible during the first three days of life.

The euthanasia of the piglets was performed according to the methods acceptable for euthanasia in the guidelines and practices approved by the Committee on Ethics in the Use of Animals (Protocol No. 2820/16). At the necropsy, samples of the cerebral cortex (frontal, temporal, parietal and occipital lobes), medulla oblongata, thalamus, hypothalamus, cerebellum, and spinal cord (cervical and lumbar sections) were collected for anatomopathological examination and RT-PCR analysis. Nervous tissue fragments were divided into three samples for conditioning: one that was placed in $10 \%$ formaldehyde for histopathological evaluations and two that were stored in a freezer at $-80^{\circ} \mathrm{C}$ until analysis.

All piglets underwent blood sampling at birth before colostrum ingestion, and the surviving piglets were evaluated at 35 days of age. Blood and serum samples were stored as described above. Due to the short half-life of colostral antibodies (Blecha, 1998), blood of piglets born from oronasally inoculated gilts was collected at intervals of $72 \mathrm{~h}$, while blood from intrauterine-inoculated piglets was collected at sevenday intervals, as the immune system response has a longer duration (Morein et al., 2002).

Neonates that remained alive from the three groups underwent clinical neurological examination to assess the function of the nervous system during the first 35 days of life. The clinical parameters evaluated daily in the piglets were neurological and behavioral parameters (head 
tilt, head turn, head stiffness, low stiffness, gait, involuntary tremors), postural reactions (proprioception and bounce), cranial nerve-related parameters (response to threat, pupillary reflex, palpebral reflexes, facial sensitivity, physiological nystagmus), myotactic and muscle tone reflexes (thoracic limbs, pelvic limbs and perianal reflex), and sensory parameters (nociception and palpation of the spine).

\subsection{Virus neutralization (VN) test}

All serum samples were tested in duplicate at the same time and were subjected to successive dilutions ranging from 1:10 to 1:5120. Samples that presented total neutralization of 100 TCID $_{50}$ of BVDV-2 at a concentration above 1:10 were considered reagents, as recommended by the "Manual of Diagnostic Tests and Vaccines of Terrestrial Animals" (OIE, 2015a). To perform the test, MDBK cells were used, and cytopathic (cp) BVDV-2 was used as the standard virus. The antibody titer considered for the reagent samples was equivalent to the reciprocal of the highest dilution in which total neutralization of $100 \mathrm{TCID}_{50}$ occurred, a fact evidenced by the absence of a cytopathic effect on the layer of MDBK cells.

\subsection{Anatomopathological analyses}

Macroscopic and microscopic analyses were performed. Among the macroscopic analyses, the ratio between the entire brain and cerebellum was measured to verify the occurrence of cerebellar hypoplasia. For this calculation, each organ was weighed individually on a precision scale. In animals with cerebellar hypoplasia, this proportion can vary between 7\%-9\% according to Pope et al. (1986).

For microscopic analysis, all samples were fixed by immersion in formalin for $72 \mathrm{~h}$ and later in $70 \%$ alcohol and were then embedded in paraffin. Samples of tissues were cut and stained with hematoxylin/ eosin (HE) and Luxol Fast Blue (Sigma ${ }^{\circledR}$ ) along with Violet Crystal staining and evaluated for the presence of lesions and demyelination in the CNS.

\section{6. $R T-P C R$}

Cerebral cortex samples (frontal, temporal, parietal and occipital lobes), medulla oblongata, thalamus, hypothalamus, cerebellum, spinal cord (cervical and lumbar sections) and whole blood samples were evaluated for the presence of BVDV by RT-PCR. All collected material were stored in sterile tubes, free of RNAses, and refrigerated at $-80^{\circ} \mathrm{C}$ until extraction.

The RNA from the samples was extracted using TRI Reagent (Sigma) and transcribed into cDNA using a High-Capacity cDNA Reverse Transcription (Applied Biosystems) kit, according to the manufacturer's instructions. The reactions to identify the presence of BVDV in the samples were performed with primers 103 (5'- TAG CCA TGC CCT TAG TAG GAC - $3^{\prime}$ ) and 392 ( $5^{\prime}$ - ACT CCA TGT GCC ATG TAC AGC - $3^{\prime}$ ), which amplify a 290-bp product (Weinstock et al., 2001).

PCR mixtures were composed of $1 \mathrm{X}$ buffer $(50 \mathrm{mM} \mathrm{KCl}, 200 \mathrm{mM}$ Tris- $\mathrm{HCl}$ ( $\mathrm{pH}$ 8.4)), $2 \mathrm{mM} \mathrm{MgCl} 2,0.2 \mathrm{mM}$ dNTPs, $1.0 \mathrm{U}$ Taq DNA polymerase, $5 \mathrm{pmol}$ of each primer, $3 \mu \mathrm{l}$ of RT-PCR product and sterile pure water at a final volume of $20 \mu \mathrm{l}$. For the amplification, a thermocycler was programmed as follows: $95^{\circ} \mathrm{C}$ for $3 \mathrm{~min}, 35$ cycles at $94^{\circ} \mathrm{C}$ for $30 \mathrm{~s}, 58^{\circ} \mathrm{C}$ for $30 \mathrm{~s}$ and $72^{\circ} \mathrm{C}$ for $40 \mathrm{~s}$, and finally, one cycle at $72{ }^{\circ} \mathrm{C}$ for $10 \mathrm{~min}$. The PCR products were subjected to a re-amplification using the same protocol described above. Amplicons were visualized in $1 \%$ agarose gel.

\subsection{Statistical analyses}

For the comparison between the average group responses, nonparametric analysis was performed for longitudinal observations (Brunner and Langer, 2000). Tukey's test was also conducted for comparing the average antibody titers of litters, and Kruskall-Wallis for comparing the antibody titers between oronasally inoculated gilts. Analyses were carried out using the "nparLD", and "agricolae" packages of the software R.

\section{Results}

\subsection{Absence of clinical signs of BVDV-2 infection in inoculated gilts}

All gilts were clinically observed until delivery to detect any clinical signs and physiological changes after inoculation, such as fever and abortion. After oronasal inoculation, the four females did not present clinical changes during the gestational period. Litters 1, 2 and 3 totaled 45 animals. Litter 4 was withdrawn from the study because the gilt presented aggressive postpartum behavior, culminating with the death of the litter. Out of the four gilts that underwent the surgical procedure for intrauterine inoculation, only two sows (5 and 6) maintained gestation and farrowed naturally and without intervention on the expected date. These two litters totaled 19 animals, with two mummified, three stillborn and 14 alive, from which six were euthanized. According to estimates of the fetal age of the mummies (Barlow, 1998), they are believed to have died at 56 and 61 days of gestation, which would have been at 11 and 16 days post-inoculation (dpi), respectively. The mummified and stillborn animals were evaluated for BVDV infection. Gilts 7 and 8 developed fever and aborted all fetuses on the first and second dpi.

3.2. Gilts seroconversion and discrepancies between the immune response of piglets from gilts exposed to both inoculation routes

Serological tests were performed to detect gilt seroconversion and the differences in immune responses against BVDV-2 of piglets from gilts exposed to the different inoculation routes. The results showed that all oronasally inoculated gilts seroconverted between two to three weeks after the experimental inoculation. Seroconversion was detected at $17,20,18$ and 22 dpi in gilts $1,2,3$ and 4, respectively, with antiBVDV-2 antibodies titers ranging from 20 to 40. Samples were considered as reagents until the last blood collection before delivery, presenting titers ranging from 10 to 20 . As data of antibody titers usually does not present normality, they were transformed into logarithms for the calculation of the average anti-BVDV-2 antibody titers of each gilt, and the serological results were statistically significant $(\mathrm{p}<0,05)$ (Table 1). On the other hand, the gilts that underwent intrauterine inoculation were not assessed for seroconversion, as the objective was only to evaluate the piglets without considering the effects of maternal protection. Regarding the serological testing of the piglets, it was possible to observe that at birth (D0) no piglets presented titers of antibodies against the agent. However, after colostrum ingestion, 85\% (12/ 14), 33\% (5/15) and 68\% (11/16) of the piglets from litters 1,2 and 3 , respectively, presented reactive serology for BVDV-2 at D3, with titers varying from 10 to 40 in litter 1,10 to 20 in litter 2 and 10 to 160 in litter 3. Titers did not remain constant during the lactational period. In

\section{Table 1}

Moment of seroconversion of the gilts inoculated oronasally with a BVDV-2 solution. Samples were taken each $72 \mathrm{~h}$ from 45 to 90 days of gestation. Titers were measured by the virus neutralization test, and are disposed as the first and last reagent samples. Titers followed by equal letters are not significantly different from each other $(\mathrm{p}<0.05)$. Dpi $=$ days post inoculation.

\begin{tabular}{llll}
\hline Gilt & Seroconversion $\left(\mathrm{dpi}^{*}\right)$ & Initial titer & $\begin{array}{l}\text { Final titer } \\
(55 \mathrm{dpi})\end{array}$ \\
\hline $\mathbf{1}$ & $17^{\circ}$ & $20^{\mathrm{b}}$ & $10^{\mathrm{b}}$ \\
2 & $20^{\circ}$ & $20^{\mathrm{b}}$ & $10^{\mathrm{b}}$ \\
3 & $18^{\circ}$ & $40^{\mathrm{a}}$ & $20^{\mathrm{a}}$ \\
4 & $22^{\circ}$ & $20^{\mathrm{b}}$ & $10^{\mathrm{b}}$ \\
\hline
\end{tabular}




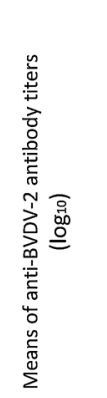

1.4

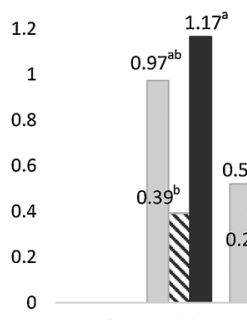

$D(0)$

$\mathrm{D}(3)$

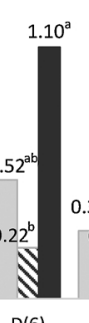

$\square$ Anti-BVDV-2 antibody mean of Litter 1

N Anti-BVDV-2 antibody mean of Litter 2

-Anti-BVDV-2 antibody mean of Litter 3

Fig. 1. Comparison of average anti-BVDV-2 antibody titers (expressed in $\log _{10}$ ) of litters born from gilts inoculated oronasally at 45 days of gestation with a BVDV-2 solution. Samples were taken each $72 \mathrm{~h}$ over 35 days after birth. Litter 1 = born from Gilt 1 ; Litter 2 = born from Gilt 2; Litter 3 =born from Gilt 3. Titers decreased over the experimental period. Statistical significance was observed in days 3 and 6 post birth. Means followed by equal letters are not significantly different from each other $(\mathrm{p}<0.05)$. $\mathrm{D}=$ Days post-birth.

litters 1 and 2, there was a strong decrease between the second and third weeks of lactation, with only $7 \%$ of the piglets (litter 1) presenting antibody titers at 18 days of age and $20 \%$ presenting titers at 12 days (litter 2), both showing low titer values (10). In litter 3, antibodies against BVDV-2 were present in low titers (10) until the end of the maternity phase in $6 \%$ of the animals, although presenting sharp variation during the experimental period. The means of antibody titers between litters were statistically significant on days three and six post birth ( $\mathrm{p}<0,05)$ (Fig. 1). VN tests indicated that the transfer of colostral immunity occurred in all litters, but the maintenance of antiBVDV-2 antibody levels was inconstant and inefficient, with a rapid decrease in titers. No piglets presented titers after weaning, which occurred at 28 days of age.

In contrast with piglets born from oronasally infected gilts, all intrauterine-inoculated piglets presented high titers of BVDV-2 antibodies at birth, ranging from 80 to 640 . All six (6/14) of the euthanized piglets were born with anti-BVDV-2 antibody titers that varied between 320 $(1 / 6)$ and $640(5 / 6)$. The titers of the eight alive piglets remained high until the end of the experimental period, reaching values up to 5120 . On days 7 and 14 post birth, the antibody titers varied from 640 to 5120. On days 21 and 28, titers varied from 320 to 5120 , and in the last day of sampling, varied from 160 to 5120 . We noted that some piglets (4/8) were able to increase their immune response against the agent during the sampling period. No statistical significance was observed between the average titers of the intrauterine inoculated litters at $5 \%$ of significance (Fig. 2). The differences between the means of antibody responses of piglets from both inoculation routes were statistically significant ( $\mathrm{p}<0,05$ ) (Fig. 3). Antibody titers of euthanized piglets from both groups are not included in the figures.

\subsection{Absence of clinical signs and pathological lesions in newborn piglets}

To assess whether the nervous system had been compromised, piglets were neurologically evaluated every day. Observations of neurological reflexes and clinical signs were recorded, as well as results of macro- and microscopic analyses. No noteworthy changes were observed, and all responses to stimuli at birth were normal but weak and became stronger over time. Thus, no characteristic traits of disease were observed. The same results were observed in the piglets of the control

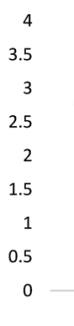

2.58

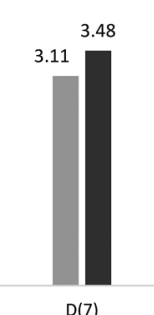

$D(7)$

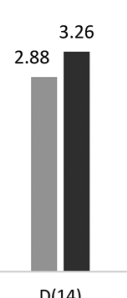

$\mathrm{D}(14)$

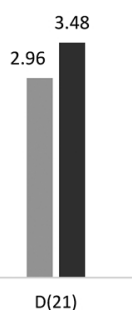

$\mathrm{D}(21)$

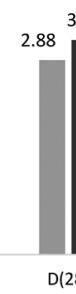

$D(30) \quad D(33) \quad D(35)$

group. Macroscopic analyses revealed that $29.5 \%$ of the piglets of the infected groups showed a cerebellar:brain ratio lower than $9 \%$, which could be indicative of cerebellar hypoplasia. The cerebellar:brain ratios, calculated based on the individual weight of each organ, are presented according to the number of piglets and are plotted as different distribution ranges of the ratios (Table 2). The rest of the animals presented either cerebellar:brain ratios within a range considered normal for the species or had values above the average. However, there was no significant difference from a Tukey's test between the piglets of the inoculated groups and the piglets of the control group. Microscopically, HE staining showed that there were no lesions characteristic of infection in the different tissues sampled. In addition, staining by Luxol Fast Blue indicated that there was no hypomyelination or tissue loss in the sections evaluated.

\subsection{Non-detection of viral RNA by RT-PCR in the samples}

RT-PCR assays were conducted to elucidate whether the piglets were born with viral particles in their organs and blood and to detect viremia in inoculated gilts. Viral RNA was not detected by RT-PCR in the CNS organs or blood samples of all piglets evaluated, including tissues from mummified and stillborn piglets. Control animals showed negative results in all tests. Regarding the oronasally inoculated females, no viremia was detected in the samples tested. Intrauterine-inoculated females were not evaluated for viremia.

\section{Discussion}

The results of this study did not support BVDV-2 as one of the etiologies of congenital tremors in piglets, which is in contrast to experimental infections with APPV in pigs and with BVDV in ruminants. Litters from oronasally inoculated gilts were born with no viruses and no antibodies against BVDV-2, which were obtained after colostrum ingestion. Conversely, all intrauterine-inoculated piglets were born non-viremic but with high anti-BVDV-2 antibody titers, ranging from 80 to 640 .

The epitheliochorial characteristic of the swine placenta, in which the maternal and fetal circulations are separated by six layers of tissues, has a primordial function in uterine protection against pathogens.

Anti-BVDV-2 antibody mean of litter 5

- Anti-BVDV-2 antibody mean of litter 6
Fig. 2. Comparison of average anti-BVDV-2 antibody titers (expressed in $\log _{10}$ ) of litters from intrauterine inoculation at 45 days of gestation with a BVDV-2 solution. Samples were taken weekly over 35 days after birth. Litter $5=$ born from Gilt 5 ; Litter $6=$ born from Gilt 6 . Titers remained high until the end of the sampling period. No statistical difference was observed between the intrauterine inoculated litters with $5 \%$ of significance. D = Days post-birth. 


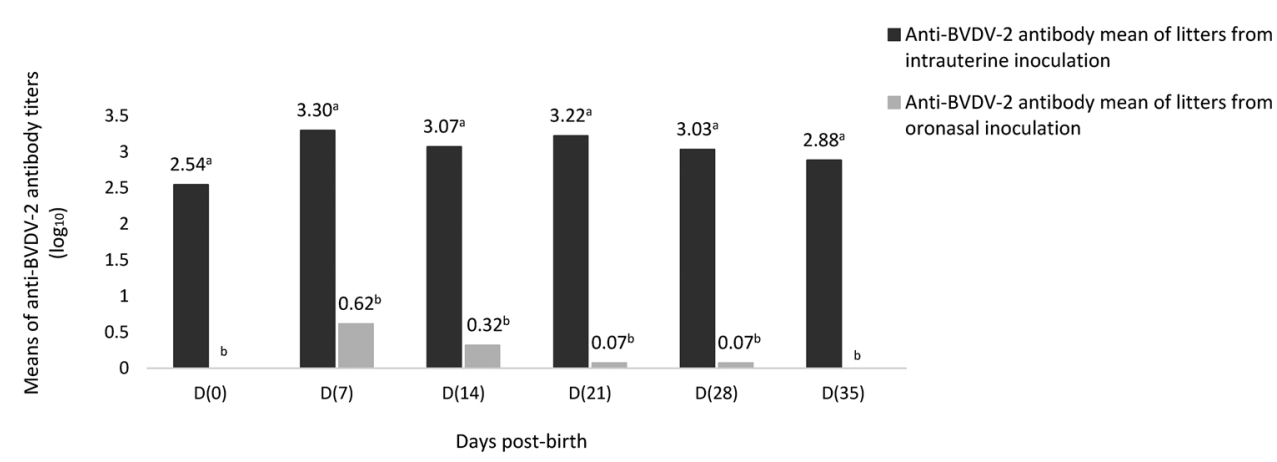

Fig. 3. Comparison between the means of antibody titers against BVDV-2 (expressed in $\log _{10}$ ) of the groups of piglets inoculated with BVDV-2 by the intrauterine route and those born from gilts inoculated by the oronasal route with the virus at 45 days of gestation. The collection dates of both groups were approximated to enable the comparison between groups. Means followed by equal letters are not significantly different from each other $(\mathrm{p}<0.05)$.

Table 2

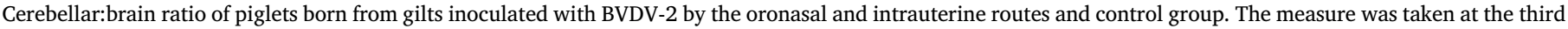

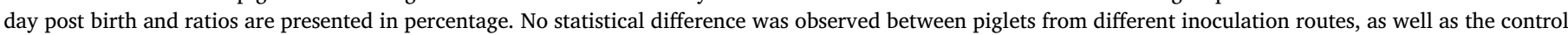
group, with $5 \%$ of significance. $n=$ number of piglets.

\begin{tabular}{|c|c|c|c|c|c|c|c|c|}
\hline \multicolumn{3}{|c|}{ Oronasal route $(\mathrm{n}=11)$} & \multicolumn{3}{|c|}{ Intrauterine route $(n=6)$} & \multicolumn{3}{|c|}{ Control $(n=6)$} \\
\hline$<9 \%$ & $9-11 \%$ & $>11 \%$ & $<9 \%$ & $9-11 \%$ & $>11 \%$ & $<9 \%$ & $9-11 \%$ & $>11 \%$ \\
\hline $\mathrm{n}=4$ & $\mathrm{n}=1$ & $\mathrm{n}=6$ & $\mathrm{n}=1$ & $\mathrm{n}=2$ & $\mathrm{n}=3$ & $\mathrm{n}=1$ & $\mathrm{n}=2$ & $\mathrm{n}=3$ \\
\hline$(36.4 \%)$ & $(9.1 \%)$ & $(54.5 \%)$ & $(16.6 \%)$ & $(33.3 \%)$ & $(50 \%)$ & $(16.6 \%)$ & $(33.3 \%)$ & $(50 \%)$ \\
\hline
\end{tabular}

However, this physical barrier also prevents the transfer of immunoglobulins from the mother to the fetus via the placenta, which makes the piglets totally dependent on the acquisition of colostral antibodies (Salmon, 1984; Salmon et al., 2009). This fact corroborates the findings of anti-BVDV-2 antibodies in piglets born from oronasally inoculated gilts and indirectly indicates that there was no vertical transmission of the virus to the piglets, which was confirmed by the lack of detection of viral RNA in the samples by RT-PCR and the negative serology at birth. In this group, the maintenance of immunity against the agent lasted between two and three weeks, despite the low antiBVDV-2 antibody titers detected. As reported in the literature, the titers of colostral antibodies remain high until two to three weeks of age (Boersema et al., 1998; Butler et al., 2009). It was observed that there was a sharp variation in the transfer of colostral immunity among the litters, since the percentage of immunized piglets ranged from $33 \%$ to $85 \%$. This fact can be attributed to the quality of colostrum of primiparous gilts, the individual variation of the gilts in their immunological response against BVDV-2, and the difference in the absorptive capacity among piglets of the same litter. In general, the titers of antibodies against BVDV in challenged pigs were low, with mean values of 20 to 40 , except the litter 3 , which presented slightly higher antibody titers probably due to the highest colostral antibody titers from gilt 3 .

All the inoculated fetuses presented seroconversion against the challenge before 70 days of gestation, a period characterized by the onset of porcine fetal immunocompetence (Barlow, 1998). BVDV-2 infection may lead to the occurrence of fetal malformations in cattle, but if the fetus survives the infection for a sufficiently extended period, non-specific maturation-related changes may occur in lymphoid tissues. As observed by Ohmann (1982), serological investigations in bovine fetuses experimentally inoculated with BVDV-2 also indicated the development of specific immunocompetence prior to the period previously reported in the literature. It is believed that the fetuses inoculated surgically in this study, after receiving the infectious stimulus, experienced an early immune response, which developed in parallel with the maturation of their immune system. Consequently, high antibody titers (range, 80-640) developed against BVDV-2 at birth, which persisted until the end of the experimental period (as high as 5120).

The results observed in the intrauterine-inoculated piglets and the persistence of the immune response as shown by increasing titers after birth leads us to suggest that there was virus infection and that BVDV-2 could still be present in the piglets' organs, continuously stimulating the immune response. Antibody repertoire studies have indicated that fetuses that survive some types of viral infections are capable of producing a specific response against the agents (Butler et al., 2009). This response to infection is initially weak and exhibits an increase near birth, when a higher level of immune system maturity is present (Sinkora and Butler, 2009). Even though information on the development of the innate immune response in pigs is scarce, it is believed that the first defense cells appear along with the first stages of hematopoietic activity (Sinkora and Butler, 2009). Lymphopoiesis is closely linked to hematopoiesis, and in swine, B cells develop in primary hematopoietic organs, such as the fetal liver, at approximately 30 days of gestation, and some T cells develop at 45 days of gestation (Sinkora et al., 2003).

This study revealed that $29.5 \%$ of the piglets in the infected groups (both oronasally and intrauterine inoculated) presented a cerebellar:brain ratio lower than $9 \%$. Conversely, $52 \%$ of the animals had a ratio above $11 \%$, including animals in the control group. Pope et al. (1986) stated that in cerebellar hypoplasia, the ratio between the cerebellum and brain may range from $7 \%$ to $9 \%$, while the normal range is from $9.5 \%$ to $11 \%$. Thus, our results contradict the data in the literature regarding the normal range of values for this species and indicate variation even among unchallenged animals. Therefore, further studies are needed to evaluate the actual ratio of these two organs in swine since the data available in the literature are old and do not appear to be accurate.

Histopathologically, fetal tissues presented no microscopic changes characteristic of infection, in contrast to the results found by Ohmann (1982). In his experiment, bovine fetuses were inoculated with a strain of BVDV-2 by an intrauterine route, which resulted in cerebellar alterations such as necrosis, depletion of the external germinative layer, and mononuclear infiltrates. In the present study, all piglets presented normal CNS tissue, with no occurrence of hypomyelination or signs of injuries. Studies of congenital tremors caused by APPV showed that piglets affected by tremors had decreased myelination in samples from the medulla (Postel et al., 2016). Similarly, Blanchard et al. (2010) reported that bovine fetuses infected with BVDV had myelin deficiencies in the medulla and cerebellum.

The lack of viral RNA detection in blood samples does not necessarily imply the absence of viremia during the period studied, as BVDV viremia in pigs may be transient, occurring over short intervals. 
Cases in which BVDV infection induced large numbers of lesions in adult pigs have been caused by viral strains that passed along previous adaptations in this species (Terpstra and Wensvoort, 1988).

Although BVDV does not pose a significant threat to swine herds, the presence of the virus in the herd may culminate in cross-reactivity with the CSFV owing to antigenic similarity. This may negatively interfere with CSFV monitoring and surveillance programs and could lead to confusion in diagnostic assays (Loeffen et al., 2009).

\section{Conclusions}

Experimental intrauterine inoculation of BVDV-2 in swine fetuses during the middle third of gestation led to the development of an intense immune response in piglets against the virus, which was not observed in piglets born from gilts oronasally inoculated with the agent. We found that experimental BVDV-2 infection did not cause clinical signs or anatomopathological lesions and did not lead to congenital tremor in pigs.

\section{Funding}

We are grateful to the São Paulo Research Foundation for a research grant (FAPESP, 2016/21421-2) and a Master's scholarship (2016/ 02982-3) and to CNPq for a research grant (409435/2016-3).

\section{Declarations of interest}

None.

\section{Conflict of interest}

None.

\section{Acknowledgments}

We are grateful to Prof. Dr. Flores EF from UFSM and Dr. Ribeiro CP from the Biological Institute of São Paulo for the inoculum and laboratory tests, to Andrea Medeiros from the Laboratory of Reproductive Viruses of FCAV for assistance with the serological analyses, and to Prof. Dr. Pedroso PMO and Prof. Dr. Macedo JTSA from the Laboratory of Pathology of UnB for assistance with the histological analyses.

\section{References}

Arruda, B.L., Arruda, P.H., Magstadt, D.R., Schwartz, K.J., Dohlman, T., Schleining, J.A., Victoria, J.G., 2016. Identification of a divergent lineage porcine pestivirus in nursing piglets with congenital tremors and reproduction of disease following experimental inoculation. PloS One 11 (2), e0150104.

Barlow, A., 1998. A guide to the investigation of porcine abortion/stillbirth. In Pract. 20, 559-564.

Blanchard, P.C., Ridpath, J.F., Walker, J.B., Hietala, S.K., 2010. An outbreak of late-term abortions, premature births, and congenital deformities associated with Bovine viral diarrhea virus 1 subtype $\mathrm{b}$ that induces thrombocytopenia. J. Vet. Diagn. Invest. 22, 128-131.

Blecha, F., 1998. Immunological Aspects: Comparison With Other Species. The Lactating Sow. pp. 23-44.

Blomström, A.L., Ley, C., Jacobson, M., 2014. Astrovirus as a possible cause of congenital tremor type AII in piglets? Acta Vet. Scand. 56, 82.

Boersema, W.J., Van Rooij, E.M., Scholten, W.J., Zwart, R.J., Kimman, T.G., Bianchi, A., 1998. Silent memory induction in maternal immune young animals. Vet. Q. 20, 89-92.

Brunner, E., Langer, F., 2000. Nonparametric analysis of ordered categorical data in designs with longitudinal observations and small sizes. Biom. J. 42, 663-675.

Butler, J.E., Lager, K.M., Splichal, I., Francis, D., Kacskovics, I., Sinkora, M., Dewald, R., 2009. The piglet as a model for b cell and immune system development. Vet.
Immunol. Immunopathol. 128, 147-170.

Cabezón, O., Rosell, R., Sibila, M., Lavín, S., Marco, I., Segalés, J., 2010. Experimental infection of pigs with border disease virus isolated from Pyrenean chamois (Rupicapra pyrenaica). J. Vet. Diagn. Invest. 22, 360-365.

Edwards, M.J., Mulley, R.C., 1999. Genetic, developmental, and neoplastic diseases. In: Straw, B.E., Dállaire, S., Mengeling, W.L., Taylor, D.J. (Eds.), Diseases of Swine, 8th ed. Iowa State University Press, Ames, pp. 695-721.

Flores, E.F., Weiblen, R., Vogel, F.S.F., Roehe, P.M., Alfieri, A.A., Pituco, E.M., 2005. A infecção pelo vírus da Diarréia Viral Bovina (BVDV) no Brasil: histórico, situação atual e perspectivas 25. Pesquisa Veterinária Brasileira, Rio de Janeiro, RJ, pp. $125-134$.

Gatto, I.R.H., Arruda, P.H., Silva, P., Harmon, K., Bradner, L., Simionato, G.C., Mechler, M.L., Schwartz, K.J., Oliveira, L.G., Arruda, B.L., 2017. First detection of atypical porcine pestivirus (APPV) in piglets with congenital tremor in South America. Proceedings of XVIII Congresso da Abraves. 301p. pp. 85-86.

Hause, B.M., Collin, E.A., Peddireddi, L., Yuan, F., Chen, Z., Hesse, R.A., Anderson, G., 2015. Discovery of a novel putative atypical porcine pestivirus in pigs in the USA. J. Gen. Virol. 96, 2994-2998.

Hoehe, P., Brito, W.D., 2012. Infecções por pestivírus de ruminantes. In: Sobestiansky, J., Barcellos, D.E.S.N. (Eds.), Doenças dos suínos, 2nd ed. Cânone editorial, Goiânia pp 352-354-285.

Loeffen, W.L.A., Van Beuningen, A., Quak, S., Elbers, A.R.W., 2009. Seroprevalence and risk factors for the presence of ruminant pestiviruses in the Dutch swine population. Vet. Microbiol. 136, 240-245.

Morein, B., Abusugra, I., Blomqvist, G., 2002. Immunity in neonates. Vet. Immunol immunopathol. 87, 207-213.

OIE-WORLD ORGANIZATION FOR ANIMAL HEALTH, 2015a. Bovine Viral Diarrhea: Manual of Diagnostic Tests and Vaccines of Terrestrial Animals. Available at:. pp. 698-710. (Accessed 04 April 2016). http://www.oie.int/fileadmin/Home/eng/ Health standards/tahm/2.04.07 BVD.pdf.

OIE - WORLD ORGANIZATION FOR ANIMAL HEALTH, 2015b. Map of CSF Official Status. Available at:. (Accessed 11 April 2016). http://www.oie.int/animal-health in-the-world/official-diseasestatus/classical-swine-fever/map-of-csf-official-status/.

Ohmann, H.B., 1982. Experimental fetal infection with bovine viral diarrhea virus. II. Morphological reactions and distribution of viral antigen. Can. J. Comp. Med. 46, 363.

Pope, A.M., Heavner, J.E., Guarnieri, J.A., Knobloch, C.P., 1986. Trichlorfon-induced congenital cerebellar hypoplasia in neonatal pigs. J. Am. Vet. Med. Assoc. 189, 781-783.

Postel, A., Hansmann, F., Baechlein, C., Fischer, N., Alawi, M., Grundhoff, A., Baumgärtner, W., 2016. Presence of atypical porcine pestivirus (APPV) genomes in newborn piglets correlates with congenital tremor. Sci. Rep. UK 6, 27735.

Ridpath, J.F., Bauermann, F.V., Flores, E.F., 2012. Flaviviridae. In: Flores, E.F. (Ed.), Virologia Veterinária, 2nd ed. Editora UFSM, Santa Maria, pp. 565-589.

Salmon, H., 1984. Immunity in the fetus and the newborn infant: a swine model. Reprod. Nutr. Dev. 24, 197-206.

Salmon, H., Berri, M., Gerdts, V., Meurens, F., 2009. Humoral and cellular factors of maternal immunity in swine. Dev. Comp. Immunol. 33, 384-393.

Scarratt, W.K., 2004. Cerebellar disease and disease characterized bydysmetria or tremors. Vet. Clin. Food Anim. 20, 275-286.

Schwarz, L., Riedel, C., Högler, S., Sinn, L.J., Voglmayr, T., Wöchtl, B., Rümenapf, T., 2017. Congenital infection with atypical porcine pestivirus (APPV) is associated with disease and viral persistence. Vet. Res. 48, 1.

Sinkora, M., Sun, J., Sinkorova, J., Christenson, R.K., Ford, S.P., Butler, J.E., 2003. Antibody repertoire development in fetal and neonatal piglets. VI. B-cell lymphogenesis occurs at multiple sites with differences in the frequency of in-frame rearrangements. J. Immunol. 170, 1781-1788.

Sinkora, M., Butler, J.E., 2009. The ontogeny of the porcine immune system. Dev. Comp. Immunol. 33, 273-283.

Terpstra, C., Wensvoort, G., 1988. Natural infections of pigs with bovine viral diarrhoea virus associated with signs resembling swine fever. Res. Vet. Sci. 45, 137-142.

Tunca, R., Haziroglu, R., Guvenc, T., Kutsal, O., Ozsoy, S.Y., 2006. Congenital cerebellar hypoplasia associated with BVD-MD virus infection in a naturally infected calf - a case report. Vet. Arhiv. 76, 453-460.

Thurmond, M.C., 2005. Virus transmission. In: Goyal, S.M., Ridpath, J.F. (Eds.), Bovine Viral Diarrhea Virus: Diagnosis, Management and Control. Blackwell Publishing, Oxford, UK, pp. 91-104.

Vannier, P., Albina, E., 1999. Bovine viral diarrhea and border disease. In: Straw, B.E., D'allaire, S., Mengeling, W.L., Taylor, D.J. (Eds.), Diseases of Swine, 8th ed. Blackwell Science, Ames.

Vogel, F.S.F., Scherer, C.F.C., Flores, E.F., Weiblen, R., de Lima, M., Kunrath, C.F., 2001. Resposta sorológica e avaliação de proteção fetal em ovelhas prenhes vacinadas contra o vírus da diarréia viral bovina (BVDV). Ciência Rural 31 (5), 831-838.

Walz, P.H., Baker, J.C., Mullaneys, T.P., Maes, R.K., 2004. Experimental inoculation of pregnant swine with type 1 bovine viral diarrhoea virus. J. Vet. Med. 51, 191-193.

Weinstock, D., Bhudevi, B., Castro, A.E., 2001. Single-tube single-enzyme reverse transcriptase PCR assay for detection of BVDV in pooled bovine serum. J. Clin. Microbiol. $39,343-346$. 